\title{
(RE) PENSANDO A CASA PRÓPRIA À LUZ DO DIREITO À CIDADE
}

\section{THINKING THE ROLE OF PRIVETY PROPRIETY TO WARDS THE RIGHT TO THE CITY}

\section{PENSANDO EN LA CASA PROPIA A LUZ DEL DERECHO A LA CIUDAD}

\author{
Bianca Siqueira Gonçalves ${ }^{1}$ \\ https://orcid.org/0000-0001-5681-9494 \\ Livia Maria de Souza Almeida Coura ${ }^{2}$ \\ https://orcid.org/0000-0003-2631-6639 \\ José Luis Vianna da $\mathrm{Cruz}^{3}$ \\ https://orcid.org/0000-0001-9869-2639
}

Submissão:10/04/2020 / Aceito: 09/05/2020 / Publicado: 20/01/2021.

\begin{abstract}
Resumo
Este estudo analisa o principal sonho de consumo da maioria dos brasileiros: a propriedade de um lugar para morar. De forma geral, discorre sobre a dinâmica capitalista na construção do espaço na cidade e como se organizam as estruturas urbanas. Especificamente, apura o papel e a importância da casa própria para o trabalhador brasileiro. Nas cidades, há acesso democrático ao solo urbano, conforme preconiza a legislação brasileira, enquanto instrumento de garantia do Direito à Cidade? De que forma se dá a atuação do capital na configuração do ambiente construído? As metodologias utilizadas evidenciaram a complexidade dos interesses em jogo. Buscou-se compreender o grau de relevância da propriedade da casa para o trabalhador brasileiro. Noutra trilha, foram analisados alguns aspectos importantes da estrutura e dinâmica da cidade, ressaltando o papel do planejamento urbano, e, neste, procurou-se reforçar as potencialidades, possibilitando mitigar a segregação socioespacial.
\end{abstract}

Palavras-chave: Cidade. Conflitos. Casa Própria. Direito à Cidade. Segregação.

\begin{abstract}
This study aims to analyze the main consumption dream of most brazilians: the ownership of a place to live. In general, it discusses how urban structures are organized and the

\footnotetext{
${ }^{1}$ Doutoranda em Planejamento Regional e Gestão da Cidade (UCAM). Analista da Secretaria de Estado de Fazenda e Planejamento do Rio de Janeiro. Campos dos Goytacazes/RJ. Brasil. biancasgoncalves@hotmail.com

${ }^{2}$ Doutoranda do Programa de Planejamento, Produção e Avaliação do Espaço Construído (UFV). Arquiteta e Urbanista. Professora Universitária do Centro Universitário UNIFAMINAS. Muriaé/MG. Brasil. livialmeidacoura.lc@gmail.com

${ }^{3}$ Pós-doutor em Desenvolvimento Territorial e Políticas Públicas (UFRRJ). Professor Permanente e Coordenador de Pesquisa do Mestrado e do Doutorado em Planejamento Regional e Gestão da Cidade (PRGCUCAM). Professor Colaborador do Programa de Pós-Graduação Mestre em Planejamento Urbano e Regional (IPPUR). Doutor em Planejamento Urbano e Regional (IPPUR). Campos dos Goytacazes/RJ. Brasil. joseluisvianna@uol.com.br
} 
capitalist dynamics in the construction of the city space. Specifically, we highlight the role and importance of home ownership in Brazil. We also answer the question weather there is a democratic access to urban land - as required by Brazilian law, - in the cities; and how does the capital acts in the shaping of the environment. The complexity of the interests at stake remains evident. We sought to understand the degree of relevance of home ownership in Brazil. Some important aspects of the structure and dynamics of the city were analyzed, highlighting the role of urban planning, and, in this, reinforcing the potentialities, enabling the mitigation of socio-spatial segregation.

Keywords: City. Conflicts. Own Home. Right to the city. Segregation.

\section{Resumen}

Este estudio analiza el principal sueño de consumo de la mayoría de los brasileños: la propiedad de un lugar para vivir. En general, analiza la dinámica capitalista en la construcción del espacio en la ciudad y cómo se organizan las estructuras urbanas. Específicamente, investiga el papel y la importancia de la propiedad de la vivienda para los trabajadores brasileños. En las ciudades, ¿existe un acceso democrático a la tierra urbana, como lo recomienda la legislación brasileña, como un instrumento para garantizar el derecho a la ciudad? ¿Cómo actúa el capital en la configuración del entorno construido? Las metodologías utilizadas mostraron la complejidad de los intereses en juego. Intentamos comprender el grado de relevancia de la propiedad de la vivienda para el trabajador brasileño. En otra vía, se analizaron algunos aspectos importantes de la estructura y la dinámica de la ciudad, destacando el papel de la planificación urbana y, en este sentido, se intentó reforzar el potencial, permitiendo mitigar la segregación socioespacial.

Palabras chave: Ciudad. Conflictos. Casa Propia. Derecho a la Ciudad. Segregación.

\section{INTRODUÇÃO}

A inquietação que motiva este estudo vem da observação do resultado de diversas pesquisas que apresentam a propriedade de um lugar para morar como o principal sonho de consumo da maioria dos brasileiros.

Centra-se a temática deste trabalho na análise da casa própria enquanto objeto de desejo da classe trabalhadora, entrelaçando o estudo com as questões do problema habitacional brasileiro, do Direito à Cidade e da segregação socioespacial. Aqui é preciso destacar que a pesquisa traz problematizações relevantes que contribuem para a discussão e não devem ser interpretadas como conclusivas.

Motivadas por esse desejo, inúmeras famílias recorrentemente comprometem grande parte de seus rendimentos em longos financiamentos, que acabam por reduzir significativamente a margem de possibilidade de gastos em outros setores relacionados a uma melhor qualidade de vida, como, por exemplo, educação, saúde e lazer. A questão é mais 
grave para as famílias de trabalhadores de baixa renda, cuja reprodução social é ameaçada, ante a impossibilidade de acesso a esses e outros bens e direitos básicos da cidadania.

Na sociedade capitalista, o problema habitacional urbano é fruto do processo de industrialização, que marcou a transferência de parte do poder econômico do campo para a cidade. Com a chegada das indústrias, a cidade passa a ofertar as condições necessárias para o desenvolvimento econômico, transformando-se em lócus de reprodução do capital e um elemento fundamental na divisão social e espacial da sociedade.

Em 1845, na obra Situação da Classe Trabalhadora na Inglaterra, Friederich Engels realizou um dos estudos que melhor desnudou a precária situação habitacional vivida pelas sociedades capitalistas pós-industriais. Segundo o autor, "os londrinos tiveram de sacrificar a melhor parte de sua condição de homens para realizar todos esses milagres da civilização de que é pródiga a cidade" (ENGELS, 2008, p.69).

Vê-se que a cidade industrial segregava a classe trabalhadora, que era empurrada para espaços predestinados a sua habitação. Esta segregação é fortemente perceptível nas cidades capitalistas atuais. No Brasil, seguimentos sociais vivem em condições precárias, desprovidas de bens e de infraestrutura mínima à manutenção da vida diária.

Assim, a segregação socioespacial sentida nos centros urbanos brasileiros é fomentada pelo mercado de terras e fortalecida e institucionalizada pelas ações do Estado. É preciso reconhecer a responsabilidade do Estado na promoção e garantia (ou não) dos direitos dos cidadãos e o papel decisivo que suas ações têm na dinâmica das desigualdades sociais, sob pena de alimentar espaços de confrontos e conflitos.

A política habitacional tem como função principal a correção dos efeitos negativos produzidos pela acumulação capitalista, propiciando o reequilíbrio social. Tem um caráter compensatório, paliativo e corretivo das desigualdades produzidas no mercado capitalista.

Ao se examinar o Programa Habitacional Minha Casa Minha Vida (PMCMV), capitaneado pelo Governo Federal, tendo sido lançado em 2009, verifica-se que, quanto aos conjuntos habitacionais entregues após 10 anos de ação, muitas famílias, principalmente as da faixa 1 (com renda familiar de até $\mathrm{R} \$ 1.800,00$ ), em nome da conquista desse objeto de desejo, aceitaram se distanciar dos seus locais de origem, dos seus locais de trabalho e até mesmo das possibilidade de acesso aos equipamentos e serviços públicos; o que, em alguns casos, agrava as condições de reprodução anteriores, ante a ausência de escolhas no acesso à moradia. 
O que se deseja é justamente o contrário: a promoção pelos governos municipal, estadual e federal, de políticas urbanas condizentes com a demanda coletiva e social, por moradia, incluindo todos os elementos da urbanização e do bem-estar universais.

A inserção do capítulo voltado para a política urbana, em especial os artigos 182 e 183 na Constituição Federal de 1988; a publicação do Estatuto da Cidade em 2001 e a criação, em 2003, do Ministério das Cidades demonstram a importância da matéria, dada a gravidade assumida historicamente (BRASIL, 1988, 2001, 2003). Por meio desses órgãos e instrumentos, é delegada aos municípios a responsabilidade maior pela condução do ordenamento da cidade em direção ao desenvolvimento e crescimento sustentáveis, sob normas e diretrizes federais. Cabe a eles o cumprimento das diretrizes estabelecidas no Plano Diretor, cuja função é o planejamento da cidade direcionado para as questões sociais, econômicas e ambientais, conforme a regulamentação federal.

É evidente que o aspecto legal não garante o ordenamento da cidade. É preciso mais, para que se atenda ao interesse público e se alcance qualidade de vida para todos. Percebe-se claramente que o Estatuto da Cidade impulsiona o Poder Público a instituir espaços urbanos com mais qualidade e menos excludentes. Resta claro que da premissa do alcance da função social da propriedade é que deveria surgir a política urbana, com seus instrumentos de gestão, controle e fiscalização. Assim sendo, acreditou-se que estariam institucionalizadas as condições, em termos dos espaços e instrumentos de participação popular, para a construção compartilhada, equitativa, da cidade, no plano formal.

Dentre os desdobramentos, no caso da moradia popular, a oferta de grandes conjuntos habitacionais em áreas periféricas, onde a terra é mais barata, contribuiu substancialmente para impulsionar o espraiamento urbano, a proliferação de um padrão urbanístico monofuncional e o estabelecimento de uma divisão territorial entre ricos e pobres (ROLNIK, 2015). A capitalização, ou a mercantilização, do território urbano prepondera sobre a socialização do espaço.

Para compreender o processo de formação da cidade é preciso analisar a ação dos diferentes agentes que produzem o espaço urbano (incorporadores imobiliários, Estado, proprietários das empresas de construção, proprietários fundiários e os grupos sociais excluídos, marginalizados do acesso aos meios de consumo coletivo) e identificar quais os interesses que os motivam. É essencial observar as relações sociais desenvolvidas em um determinado espaço e examinar de que modo elas influenciam os contornos desse espaço. 
Os conjuntos habitacionais periféricos resolvem um problema individual (unidade familiar), possibilitando a aquisição da habitação a preço acessível, e criam-se novos problemas urbanos e sociais que afetam coletivamente a cidade. Agrava-se o problema das periferias precárias submetidas à violência político-administrativa, policial e da criminalidade, assim como os problemas de integração e sociabilidade cidadãs, na medida em que a segregação é aprofundada.

Por que as desigualdades socioespaciais não são sequer mitigadas, ou enfrentadas, no caso brasileiro em geral? O "equilíbrio social" e o "ordenamento espacial" não passam de um discurso tecnocrático, impregnado de ideologia/interesses de grupos e corporações de classe. Viu-se que a ação dos agentes sociais que fazem e refazem a cidade ocorre dentro de um marco jurídico que regula a sua atuação.

Esse marco não é neutro, é resultado de uma longa luta pela Reforma Urbana e de uma longa prática que reflete a dominância dos interesses dos agentes detentores da terra, do capital e dos imóveis, e constitui-se em uma retórica ambígua, que permite que haja transgressões de acordo com os interesses do agente dominante, numa articulação dos grupos mais poderosos.

Há, entretanto, denominadores comuns que os unem: um deles é a apropriação de uma renda da terra. Por outro lado, a ação desses agentes serve ao propósito dominante da sociedade capitalista, que é o da reprodução das relações de produção, implicando a continuidade do processo de acumulação, ao lado da tentativa de minimizar conflitos de classe. Assim, a cidade, com tudo o que ela representa em termos produtivos e de local da reprodução da força de trabalho, cresce ao sabor dos interesses privados (PIQUET; RIBEIRO, 2001). As decisões acerca da urbanização são decisões políticas. E tais decisões, no Brasil, têm peculiaridades perversas, advindas da relação entre sociedade e Estado. Os processos decisórios acabam por ser influenciados por padrões históricos estruturadores e organizadores de tais relações.

Constata-se que, independente da classe social, muitas vezes a conquista da casa própria revela que as famílias estão dispostas a aceitar condições que tornam suas vidas prejudicadas em diversos aspectos, o que se prolonga por longos períodos de tempo, ou até mesmo de forma definitiva, refletindo o monopólio dos interesses mais imediatos das frações dos capitais envolvidos no negócio da habitação enquanto uma mercadoria no mercado capitalista de bens de consumo. 
Nessa trilha, este artigo tem como objetivo abordar o tema da casa própria a partir de uma análise de sua representação enquanto objeto de desejo da classe trabalhadora, entrançando o estudo com as questões do problema habitacional brasileiro, do Direito à Cidade e da segregação socioespacial, trazendo elucidações não conclusivas.

\section{METODOLOGIA}

Trata-se de um estudo qualitativo que tem como metodologia de pesquisa uma revisão da bibliografia sobre a origem da casa como mercadoria e objeto de desejo do trabalhador.

Ampliando-se a análise, revisa a bibliografia sobre o problema habitacional brasileiro e a questão da segregação socioespacial, à luz do Direito à Cidade.

Com base nos estudos de Nabil Bonduki (1998), foi possível compreender o significado da casa própria para o trabalhador. Lefebvre (2006) clareia as acepções do Direito à Cidade e, através da abordagem de David Harvey (2014), destaca-se o papel do Estado enquanto agente regulador do acesso à moradia no sistema econômico capitalista.

\section{DESENVOLVIMENTO}

O que, à primeira vista, parece ordem, é o caos para uma grande parte dos moradores das cidades. O sistema capitalista está gerando graus de desordem inéditos, enquanto alguns economistas o vêm como portador dos elementos para garantir o tão buscado equilíbrio. A cidade capitalista tornou-se uma mercadoria a serviço do capital. Em consequência, o acesso ao solo e aos equipamentos de consumo coletivo é precário ou inexistente para a maioria trabalhadora dos seus habitantes (BOURDIEU, 1989). O privado impõe-se ao público; os interesses econômicos empresariais superpõem-se aos interesses sociais e coletivos.

No capitalismo, a cidade é o produto, no espaço, dos processos de produção, circulação e consumo. A criação desse espaço é carregada de contradições e tensões, uma vez que nele estão envolvidos os interesses do capital em seus diversos segmentos, da força de trabalho e do Estado (PIQUET; RIBEIRO, 2001). 
A cidade capitalista é o lugar privilegiado de ocorrência de uma série de processos sociais, onde a reprodução social está condicionada pelo processo de acumulação de capital. A urbanização capitalista é, antes de tudo, uma multiplicidade de processos de apropriação do espaço. Para uns, a terra tem valor de uso; para outros, valor de troca. O valor de uso diz respeito à utilidade social, para atender às necessidades coletivas universais; o valor de troca diz respeito ao uso da cidade, do seu solo e do ambiente construído, para fins de acumulação privada de capital; ou seja, ao uso da cidade como mercadoria, submetida aos interesses do capital privado empresarial.

A dinâmica mais recente do processo urbano trouxe com ela dramáticas transformações no estilo de vida. As políticas urbanas neoliberais, que ganharam força no Brasil nas últimas décadas, vêm sendo decisivas no sentido de definir a (re)estruturação do espaço urbano. Para além do aspecto econômico, as mudanças impulsionadas pela globalização afetam a produção do espaço urbano e atingem diretamente a formulação e legitimação de paradigmas nas políticas urbanas. Dessa forma, a adoção das diretrizes e concepções neoliberais que configuraram as relações entre capital, Estado e sociedade gerou profundas repercussões sobre o lugar e o papel da cidade no processo de acumulação.

Com o neoliberalismo, a cidade passa a ser tratada como espaço direto do capital mediado pela lógica da valorização do capital e da financeirização. Submetida ao movimento espontâneo do mercado, a cidade passa a funcionar como uma verdadeira empresa e como tal passa a ser conduzida (VAINER, 2011).

Se o solo urbano não tivesse valor e não gerasse renda, evidentemente não despertaria interesse por parte da iniciativa privada e dificilmente haveria a pujança que o mercado imobiliário adquire na cidade. Por isso, é fundamental que o Poder Público administre o conflito entre o interesse geral e o aumento do valor de troca e da renda do solo por parte de alguns interessados privados, de tal forma que o ordenamento urbano acaba sendo capturado por esses princípios. $\mathrm{O}$ interesse geral não pode ser preterido em prol dos interesses econômicos de alguns. Caso o Poder Público não consiga administrar o conflito entre o interesse geral e os interesses econômicos de determinado grupo, a ocupação desordenada do solo e a especulação imobiliária descontrolada aprofundarão seu domínio sobre as formas da expansão urbana.

No estudo do processo de formação do espaço urbano de uma cidade, deve-se atentar para o fato de que, na medida em que o espaço é re-des-estruturado - por meio de 
arranjos e combinações entre variáveis e interesses - é responsável pelo direcionamento social do espaço a variável ou os interesses dos agentes que tiverem mais poder em relação aos demais. Dessa forma, se os interesses dos agentes do sistema econômico preponderarem, como acontece, via de regra, teremos a variável econômica conduzindo a formação e a organização da sociedade, ou seja, predominarão os interesses empresariais, do lucro.

A partir dessas considerações, o artigo reflete as seguintes questões: qual a importância da casa própria para os trabalhadores? A opção pela casa própria demanda a abdicação de algum direito?

Nabil Bonduki (1998) expõe o mecanismo político que dissemina o conceito da casa própria no Brasil. Para o trabalhador, numa perspectiva mesmo que ilusória, representa ascensão social, bem como estabilidade financeira e familiar. Sendo assim, a conquista da casa própria traz consigo a valorização do trabalho, "demonstrando que ele compensa, gera frutos e riqueza" (BONDUKI, 1998, p.84).

Para compreensão desse processo cultural, político e econômico que alimenta o fetichismo da casa própria, a reflexão proposta por esse artigo deve-se conduzir por questões tais como a valorização da propriedade individual, privada; a concretização da habitação como mercadoria e não como um direito e a disseminação do ideal da casa própria, supervalorizado diante da forte representação de "condições mais favoráveis de sobrevivência numa sociedade em que os direitos sociais inexistem ou são pouco respeitados." (BONDUKI, 1998, p.308).

Segundo Bachelard (1993), a casa é "um verdadeiro cosmos", "o nosso primeiro universo". A casa é o abrigo primordial do homem, ela o acolhe e o faz sonhar. Na casa ele pode desfrutar a solidão. De acordo com o autor, "a casa é uma das maiores forças de integração para os pensamentos, as lembranças e os sonhos do homem" (BACHELARD, 1993, p. 26). Ainda quando simples e cheia de defeitos, no devaneio torna-se reconfortante, dá estabilidade.

Pallasmaa (2017) conceitua o ato de habitar como o modo básico de alguém se relacionar com o mundo, sendo fundamentalmente um intercâmbio e uma extensão. Isso porque, se por um lado o habitante se acomoda no espaço e o espaço se acomoda na consciência do habitante, por outro esse lugar se converte em uma exteriorização e uma extensão de seu ser, tanto do ponto de vista físico quanto mental. 
Do que se vê que a casa carrega em si diversas funções e sentimentos. Ela representa primordialmente abrigo e proteção, mas também alimenta o sentimento de liberdade: é em sua casa que o cidadão se sente à vontade, experimenta a sensação de autonomia, de privacidade, mas, também, de propriedade e patrimônio, numa sociedade em que a casa tem valor de troca. A casa própria, por sua vez, representa a formação de um patrimônio e a possibilidade de melhoria de vida.

Em tese, a propriedade permite que a família incorpore mais valor, mais recursos obtidos através de um trabalho incessante, adicionado, a fim de remodelar e melhorar permanentemente o espaço físico, de modo que reflita e expresse o cotidiano familiar (BONDUKI, 1998). Por esse motivo, percebe-se que a política habitacional está na maioria das vezes calcada na questão da propriedade desse abrigo, com o cidadão disposto a buscála sem medir sacrifícios.

Contextualizando o processo de urbanização e relacionando-o com o conceito da casa como mercadoria, destaca-se a acelerada urbanização brasileira comprovada por índices que apontam, em 1940, uma urbanização da população de 31\%, passando para 75\%, em 1990, chegando em 81\%, em 2001 e a 84,72\% em 2015 (IBGE, Pesquisa Nacional por Amostra de Domicílio, 2015). Essa realidade não encontrou crescimento proporcional nos índices de geração de emprego, oferta de moradia, infraestrutura, serviços e equipamentos urbanos. Esse cenário é percebido na baixa qualidade do ambiente urbano das grandes cidades e nas áreas de ocupação irregular autoconstruídas e precárias das cidades brasileiras em geral.

A princípio, o problema da escassez de moradia foi resolvido com a construção das vilas operárias, geralmente contíguas às fábricas. Junto à sensação de segurança e melhores condições da reprodução da força de trabalho, essa prática funcionava também como um instrumento de controle, vez que, "como era de conhecimento geral na década de 1930, proprietários de casas agoniados pelas dívidas não faziam greves." (HARVEY, 2014).

Ademais, representavam também uma diminuição nas despesas dos operários com sua própria reprodução, permitindo que os salários fossem rebaixados. Porém, essa foi uma solução somente aplicada quando a quantidade de trabalhadores era relativamente pequena.

No Brasil, o dinamismo experimentado no processo de industrialização na era Vargas fez com que essa massa de trabalhadores fosse percebida como uma força importante a ser governada, a fim de não trazer instabilidade para a organização política do país. $\mathrm{O}$ 
Estado viu-se compelido a concretizar políticas públicas minimamente capazes de oferecer condições para atendimento das necessidades básicas da população, dentre elas a moradia.

A obsessão pela aquisição da casa própria também foi fomentada pelo estabelecimento de um valor fixo de remuneração denominado salário mínimo. O valor do trabalho foi nivelado por baixo, o que logo ocasionou a deterioração do salário. Quem dependia exclusivamente dele, viu na aquisição da casa própria a solução definitiva para amenizar sua maior inquietação causada por uma despesa com aluguel, que abocanhava a cada dia uma maior parcela de seu rendimento, ou que não podia pagar, o que gerou, dentre outros fatores, os processos de ocupação precária e favelização.

De certa forma, à medida que a urbanização avança, os meios de reprodução da força de trabalho urbana também se mercantilizam, marcando a origem do conceito da casa como mercadoria e de uma ideologia alimentada pelo Estado, que mantém o incentivo à aquisição da casa própria como forma de aquietar a insatisfação social e manter a hegemonia das classes dominantes, desviando a classe trabalhadora de maiores lutas políticas e sindicais (ARAÚJO, 2007).

A lógica da propriedade privada individual é a base da maior parte das políticas habitacionais desenvolvidas ao longo dos anos. Entretanto, essas políticas não conseguem atingir a todos, visto que a população que vive nas favelas, áreas de ocupação ou coabitam em um espaço inadequado não possuem renda compatível com o valor da mercadoria e, portanto, são excluídas dessa possibilidade. Até recentemente, a política habitacional privilegiava as construções voltadas para as classes médias e de alta renda.

Segundo Lefebvre (2001), o Direito à Cidade é também o direito a sua apropriação coletiva, universal, sendo uma forma superior dos direitos (engloba o direito à liberdade, à individualização na socialização e o direito ao morar). O direito à apropriação, bem distinto do direito à propriedade, está, portanto, implícito no Direito à Cidade.

Sobre as raízes desse direito, é necessário buscar os referenciais em 1967, ano em que Lefebvre escreveu a obra manifesto "Direito à Cidade". Trata-se de um conceito acadêmico e de luta social. A cidade é vista como obra coletiva, onde deve predominar o valor de uso; é um direito que deve ser exercido em sua plenitude e dispensado a todos.

Para Lefebvre (2006), o Direito à Cidade afirma-se como um apelo, como uma exigência e o urbano é um lugar de encontro, com prioridade do valor de uso. Assim sendo, "não se pode evitar o conflito" na medida em que o "urbano se baseia no valor de uso", 
irredutível e imanente ao humano (LEFEBVRE, 2006), incompatível com o uso da cidade como mercadoria.

Direito à cidade implica a ótica predominante do valor de uso, para que todos possam usufruir da riqueza socialmente produzida. Ou seja, é uma forma de alterar a dinâmica da cidade como mercadoria (LEFEBVRE, 2001; HARVEY, 2001). Ao invés de ver cada pedaço da cidade como valor de troca, é preciso pensar a cidade, em sua totalidade, como valor de uso, dar uma finalidade social a ela e privilegiar sua função enquanto catalizadora de direitos sociais. O Direito à Cidade se torna bem mais do que o direito individual de ter acesso a serviços públicos de qualidade, significa ter mais liberdade de viver e experimentar os espaços que criamos e recriamos constantemente; é, portanto, o espaço da festa, da sociabilidade.

O conceito de Direito à Cidade, desse modo, não pode ser compreendido apenas como o direito de visita ou de retorno às cidades originárias. Para Lefebvre (2001, p. 134), "direito à cidade se manifesta como forma superior dos direitos" e engloba os direitos "à liberdade, à individualização na socialização, ao habitat e ao habitar”. Nesse sentido, “(...) o direito à obra (à atividade participante) e o direito à apropriação (bem distinto do direito à propriedade), estão implicados no direito à cidade". É a condensação do direito à vida urbana, transformada, renovada.

O Direito à Cidade é compreendido para além do usufruto de benefícios públicos urbanos: manifesta-se principalmente como o direito de modificação do espaço urbano. Ao compreender a cidade enquanto um produto que gera lucro (feita para o consumidor economicamente privilegiado), a mudança planejada para a cidade, muito embora, em tese, propicie melhores condições da vida cotidiana para boa parte dos moradores, reforça a segregação urbana de numerosa fatia da população.

Assim, o Direito à Cidade, antes de ser um projeto revolucionário, é também o direito de participar da construção do projeto de cidade, que envolve seus habitantes (os diversos atores sociais) e o Poder Público. A existência da pressão econômica, por parte dos proprietários, tende a aumentar as desigualdades socioespaciais, resultantes de determinadas políticas públicas a serviço de determinados grupos sociais.

Para David Harvey (2012, p.73), "vivemos num mundo onde os direitos de propriedade privada e a taxa de lucro se sobrepõe a todas as outras noções de direito". Como consequência do elevado valor da moradia, grande parte da população não consegue adquirir 
esse bem e, na prática, o direito à habitação não é tratado como fundamental para a vida humana; ele é entendido principalmente como uma mercadoria, um tipo de investimento, um negócio voltado para a acumulação do capital.

A casa própria constitui o sonho de uma parcela considerável da população brasileira, é um objetivo de vida, a concretização de um sentimento de segurança e tranquilidade perseguido por muitas famílias, construído pela ideologia da propriedade privada, do patrimônio, da posse ou propriedade de um bem, que pode ser transformado em dinheiro; assim como, para os mais pobres, o acesso a um dos meios de reprodução da vida mais fundamentais.

A realidade dinâmica da produção da habitação, onde o resultado deve ser capaz de ressarcir os gastos e possibilitar o lucro, eleva o preço da moradia e inviabiliza sua aquisição por grande parte da população, que é excluída do mercado imobiliário formal e encontra na autoconstrução, nas favelas e periferias da cidade as formas possíveis de acessarem a habitação (AZEVEDO, 2007). A política pública habitacional recorre ao discurso do "sonho da casa própria”. Contudo, o Estado como agente modelador do território acaba por reforçar a continuidade de territórios periféricos se ausentando do papel fundamental de diminuidor das "desigualdades urbanas". Esse processo se concretiza na privação da oferta de meios de consumo coletivo, dos "serviços públicos", da infraestrutura urbana ou das condições de segurança, proteção, de reprodução, física e social. Vê-se, ademais, que as ações e omissões do Estado decorrem das relações de poder que o capturam.

Sem dúvida, a positivação da função social da propriedade deve ser considerada um avanço. Entretanto, a lei que responde à questão conceitual não esgota a questão da desigualdade estrutural. O aparato legal é resultado dos conflitos existentes e dos embates sociais; mas é limitado, na medida em que os conflitos e lutas não superam as questões de fundo.

Segundo Harvey (2012), o espaço urbano, tornado mercadoria, faz com que sua conquista seja determinada pelo mercado imobiliário que alimenta um grande conflito de interesses. A título de exemplo, áreas onde por muitos anos viviam populações de baixa renda, quando valorizadas por sua localização centralizada ou algum outro interesse do mercado, adquirem um valor que provoca a expulsão dos seus “donos” por direito, que veem suas terras e construções capturadas pelo capital em nome da ideologia do desenvolvimento e do progresso. 


\section{CONSIDERAÇÕES FINAIS}

Buscou-se, neste trabalho, evidenciar a ideologia da casa própria, enraizada no desejo coletivo da população, que aponta que um dos nós da realização do direito à habitação como o direito à cidade, na concepção de Lefebvre, se concentra nesta visão da casa como mercadoria, sujeita aos efeitos do capitalismo e, portanto, distante da possibilidade de toda a população.

A escolha do lugar para morar é decisiva para propiciar a inclusão socioterritorial e a ampliação do acesso aos serviços urbanos. Neste trabalho, as questões apresentadas são considerações que foram articuladas a partir dos autores eleitos, não sendo respostas totais, mas sim problematizações.

Seria a propriedade da habitação realmente a provedora dessa tranquilidade e segurança familiar? Ela não se mostra solução e sim um problema quando ofertada em território segregado da cidade, como observamos nos condomínios populares do PMCMV. Ela também representa uma ilusão para o trabalhador classe média que, frente aos juros praticados nos financiamentos, compromete todos os outros sonhos ao realizar o da casa própria.

Torna-se importante perceber como as políticas habitacionais voltadas para a aquisição da moradia reforçam o fetiche da casa própria, sendo concebida como objeto de desejo, imbuída do sentimento de posse, o que se revela pouco eficiente ao tratar o problema do déficit habitacional apenas de forma quantitativa. É necessário compreender a definição multidimensional do morar, que inclua o acesso aos direitos sociais.

Conforme argumenta Sen (2000), os agentes podem ser considerados privados de levar a vida que desejam socialmente sob vários aspectos, sejam eles legais, políticos, sociais ou econômicos. Assim, o acesso à moradia digna é condição básica de cidadania e meio de correção de injustiças históricas (SILVA, 1995).

Sabemos que o ato de morar possui significado político, social e econômico. Como vimos, “o abrigo é uma necessidade do homem, já a casa própria é um objeto que inclui o indivíduo e altera seu status na sociedade. A casa é objeto de consumo e a necessidade de morar fica alterada pela necessidade de obter" (ARAÚJO, 2007). 


\section{REFERÊNCIAS}

ARAÚJO, Ana Cristina da Silva. A casa (própria) alugada no Programa de Arrendamento Residencial: questões da política pública habitacional e o caso do Residencial Cavalari na cidade de Marília-SP. 2007. Tese de Doutorado. Universidade de São Paulo.

AZEVEDO, Sérgio de. Desafios da Habitação Popular no Brasil: políticas recentes e tendências. (IN) Habitação social nas metrópoles brasileiras: uma avaliação das políticas habitacionais em Belém, Belo Horizonte, Porto Alegre, Recife, Rio de Janeiro e São Paulo no final do século XX / Organizador Adauto Lucio Cardoso. Porto Alegre: ANTAC (Coleção Habitare), 2007.

BACHELARD, Gaston. A poética do espaço. São Paulo: Martins Fontes, 1993.

BONDUKI, Nabil. Origens da Habitação Social no Brasil. São Paulo: Estação Liberdade, 1998.

BOURDIEU, Pierre. O poder simbólico. Lisboa: DIFEL; Rio de Janeiro: Bertrand Brasil, 1989.

BRASIL. Constituição (1988). Constituição da República Federativa do Brasil de 1988. Disponível em: <http://www.planalto.gov.br/ccivil_03/Constituicao/ConstituicaoCompilado.htm>. Acesso em: 21 maio 2019.

Lei no 10.257, de 10 de julho de 2001. Disponível em <http://www.planalto.gov.br/ccivil_03/leis/LEIS_2001/L10257.htm>. Acesso em: 21 maio 2019.

ENGELS, Friedrich. A situação da classe trabalhadora na Inglaterra. São Paulo: Boitempo Editorial, 2008.

HARVEY, David. Cidades rebeldes. São Paulo: Ed. Martins Fontes, 2014.

Direito à Cidade. Lutas Sociais, São Paulo, n 29, dezembro 2012. Disponível em <http://revistas.pucsp.br/index. php/ls/article/view/18497>. Acesso em 07 jun. 2019.

A produção capitalista do espaço. São Paulo: Annablume, 2001.

IBGE - Pesquisa nacional por amostra de domicílios: síntese de indicadores 2015 / IBGE, Coordenação de Trabalho e Rendimento. - Rio de Janeiro: IBGE, 2016. 108p. https://biblioteca.ibge.gov.br/visualizacao/livros/liv98887.pdf Acesso em: 07 jul. 2019.

LEFEBVRE, Henri. O Direito à Cidade. São Paulo: Centauro, 2006. 
A cidade do capital. Rio de Janeiro: DP\&A, 2001.

PALLASMAA, Juhani. Habitar. São Paulo: Gustavo Gili, 2017.

PIQUET, Rosélia.; RIBEIRO, Ana Clara Torres. O desenvolvimento urbano em questão. 2. ed. Rio de Janeiro: IPPUR/UFRJ, 2001.

ROLNIK, Raquel et al. O Programa Minha Casa Minha Vida nas regiões metropolitanas de São Paulo e Campinas: aspectos socioespaciais e segregação. Cadernos Metrópole, v. 17, n. 33, p. 127-154, 2015.

SEN, Amartya. Desenvolvimento como liberdade. São Paulo: Companhia das Letras, 2000.

SILVA, Carlos Eduardo da Costa. Habitação Rural: uma proposta de racionalização pela autoconstrução. Seropédica: Edur, 1995.

VAINER, Carlos. Cidade de Exceção: reflexões a partir do Rio de Janeiro. 2011. Disponível em:

<https://br.boell.org/sites/default/files/downloads/carlos_vainer_ippur_cidade_de_excecao_ reflexoes_a_partir_do_rio_de_janeiro.pdf>. Acesso em: 15 jul. 2019. 